\title{
A tragédia do preconceito: o negacionismo e o debate sobre o uso medicinal da maconha
}

The tragedy of prejudice: denial and the debate on medicinal use of marijuana

\author{
Paula da Conceição Fabrício* \\ Paulo Amarante**
}

\begin{abstract}
Resumo - O presente artigo apresenta o debate do campo psiquiátrico sobre a maconha no Brasil. As entidades selecionadas para representar esse campo foram: a Associação Brasileira de Psiquiatria, o Conselho Federal de Medicina e a Plataforma Brasileira de Políticas sobre Drogas, que engloba o Centro Brasileiro de Estudo de Saúde, a Associação Brasileira de Saúde Coletiva, a Associação Brasileira Multidisciplinar de Estudos sobre Drogas e a Associação Brasileira de Saúde Mental. Um breve histórico sobre a Cannabis no mundo e no Brasil foi apresentado, seguido das práticas discursivas publicadas por meio de notas, manifestações e documentos divulgados nos sites das instituições. Foi observado que há divergências entre as entidades multidisciplinares e as estritamente médicas nos casos pesquisados. As entidades médicas têm se posicionado apresentando informações que não encontram respaldo nos campos sociais, jurídicos e de segurança pública e de forma ambivalente quando a questão é o uso medicinal da Cannabis.
\end{abstract}

Palavras-chave: maconha; política pública; discursos; psiquiatria.

\begin{abstract}
The present paper explores the debate in the psychiatric field about marijuana in Brazil. The entities selected to represent this field were: the Brazilian Psychiatric Association, the Federal Council of Medicine, and the Brazilian Drug Policy Platform, which includes the Brazilian Center for Health Studies, the Brazilian Association of Collective Health, the Brazilian Multidisciplinary Association for Drug Studies, and the Brazilian Association of Mental Health. A brief history about cannabis in the world and in Brazil is presented, followed by the discursive practices contained in public notes and documents published on the institutions' websites. It was observed that there are disagreements between multidisciplinary and strictly medical entities in the cases researched. The medical entities have positioned them-
\end{abstract}

\footnotetext{
* Médica psiquiatra, mestra em saúde pública pela Escola de Saúde Pública Sergio Arouca/Fiocruz. E-mail: paula fabricio@gmail.com. ORCID: https://orcid.org/0000-0002-4587-5308.

** Médico psiquiatra, doutor em saúde pública, pesquisador sênior da ENSP/Fiocruz. E-mail: pauloamarante @gmail.com. ORCID: https://orcid.org/0000-0001-6778-2834.
} 
selves by presenting information that does not find support in the social, legal, and public security fields and in an ambivalent way when the issue is the medicinal use of cannabis.

Keywords: marijuana; public policy; discourses; psychiatry.

\section{Introdução}

A questão do uso medicinal da maconha vem ganhando cada vez mais espaço na sociedade brasileira e no mundo. O seu histórico de substância classificada como ilícita e a sua proibição ao longo do tempo, com o intuito de controle sobre parcela da sociedade, vem gerando discussões político-ideológicas que prejudicam um olhar mais ampliado sobre o tema e que sustentam mitos, preconceitos e sofrimento de parte da população brasileira, que fica exposta às violências de Estado. Tendo isso em vista, este artigo fará um breve resumo sobre as políticas que envolvem a maconha no mundo e no Brasil, abordando a forma pela qual as entidades do campo psiquiátrico vêm tratando o tema do seu uso medicinal, para que reflexões possam ser feitas visando avançar em um debate norteado pela ciência.

Para representar o campo psiquiátrico brasileiro dentro dessa discussão foram selecionadas as seguintes entidades: o Conselho Federal de Medicina (CFM), a Associação Brasileira de Psiquiatria (ABP) e a Plataforma Brasileira de Políticas sobre Drogas (PBPD), que engloba instituições como o Centro Brasileiro de Estudos de Saúde (Cebes), a Associação Brasileira de Saúde Coletiva (Abrasco), a Associação Brasileira Multidisciplinar de Estudos sobre Drogas (Abramd) e a Associação Brasileira de Saúde Mental (Abrasme).

A metodologia implicou a identificação e seleção das notas públicas e manifestações encontradas nos sites das entidades, publicadas entre 2015 e 2020. Os documentos selecionados foram submetidos ao método de análise das práticas discursivas e produção de sentidos de acordo com os critérios propostos por Spink et al. (2013). Para a autora, as práticas discursivas são as maneiras pelas quais sentidos são produzidos e posicionamentos são feitos em relações sociais cotidianas.

\section{A maconha no mundo e no Brasil}

A maconha é uma planta de utilização milenar proveniente da Ásia Central e teve seu uso generalizado no período neolítico. Acredita-se que ela seja cultivada desde o início da agricultura, há cerca de 12.000 anos, e com o decorrer do tempo o seu uso foi se diversificando, sendo utilizada como fibra para a produção de tecidos, cordas e papel; em rituais 
sagrados, como é o caso dos rituais indianos de adoração ao deus Shiva, do budismo tântrico e do rastafarianismo; como substância inebriante de uso social; e também como substância medicinal (SANTOS, 2009).

Os primeiros relatos do uso medicinal foram feitos pelos chineses há cerca de 2.737 AEC (SANTOS, 2009). A planta era reconhecida por tratar dores reumáticas, constipação intestinal, desarranjos no sistema reprodutivo feminino, malária e tantos outros males. Aproximadamente na mesma época, os indianos a usavam para tratar nevralgia, dor de cabeça, dor de dentes, reumatismos, inflamações, raiva, nervosismo, problemas respiratórios, diarreia, cólicas, falta de apetite, retenção urinária e infeções de pele, além de também recorrer aos poderes afrodisíacos da planta para os problemas reprodutivos. Dois mil anos mais tarde (711 AEC-788 AEC), a Cannabis foi incorporada aos tratados médicos árabes usados na Península Ibérica pelos mouros, sendo indicada como diurético, digestivo, para amenizar a dor de ouvido e para "acalmar o cérebro" (FRANÇA, 2018).

Os primeiros relatos médico-científicos sobre o uso medicinal da Cannabis foram publicados no século XIX por Willian O'Shaughnessy, professor irlandês de química da Faculdade de Medicina de Calcutá, que escreveu sobre um Caso de tétano curado com preparação de cânhamo (Cannabis indica), em 1839; e o segundo em Notas sobre a preparação do cânhamo indiano ou gunjah (Cannabis indica), em 1943. Esses estudos foram amparados por relatos de casos que sugeriam que a planta poderia ser utilizada no tratamento do reumatismo, da hidrofobia, da cólera, do tétano e da convulsão. Para o historiador França (2018), um dos grandes feitos desse professor foi conseguir introduzir a Cannabis e suas possibilidades terapêuticas no meio científico europeu. Na mesma época, a psiquiatria também começou a se interessar pelo estudo da planta e, em 1845, Jacques-Joseph Moreau publicou Do haxixe e da alienação mental: estudos psicológico (FRANÇA, 2018).

Mesmo com os seus diversos usos, incluindo o medicinal, a planta passou por vários estados de proibição. Questões relacionadas ao controle de parte da sociedade, geralmente considerada em vulnerabilidade econômica e social, estavam presentes desde os primeiros atos de proibição ao uso da planta (BEWLEY-TAYLOR; BLICKMAN; JELSMA, 2014), e tal fato foi contínuo ao longo da história. No Brasil, o uso da substância ficou culturalmente relacionado aos negros escravizados e, em 1830, por meio de uma decisão da Câmara Municipal do Rio de Janeiro, houve criminalização do uso e da comercialização do pito do pango (o pito era um tipo de cachimbo utilizado pela população negra para fazer uso da maconha). Tal medida previa uma multa para quem comercializasse o pito do pango e prisão de três dias para os "escravos" e outros que dele fizessem uso (DORIA, 1958). Saad (2018) analisou que a referência explícita aos negros escravizados revela a repressão do consumo da substância como estratégia de controle dessa população. 


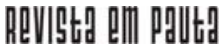

\} A TRAGÉDIA DO PRECONCEITO - FABRÍCIO, P. C.; AMARANTE, P. \}

DOI: $10.12957 /$ REP.2022.63528

A partir da pressão de grupos religiosos que buscavam uma ordem social embasada na moralidade; de interesses comerciais de países que buscavam quebrar monopólios comerciais para expandir o seu mercado, como por exemplo a ação dos EUA diante da Inglaterra e da China, que gerou a Guerra do Ópio; e o interesse médico em ter poder sobre a prescrição das substâncias, teve início um processo de controle internacional sobre algumas substâncias psicoativas. O ópio foi a primeira substância a ser controlada, seguido pela cocaína, no início do século XX, e esse processo viria a inserir a maconha. Nas primeiras convenções em que foi feita a tentativa da inclusão da planta na lista de substâncias controladas, algumas nações não estavam convencidas de que ela deveria ser incorporada. Os estudos encomendados para analisar os efeitos da planta não recomendavam a sua proibição, como foi o caso da pesquisa que gerou o Relatório da Comissão Indiana para Drogas do Cânhamo, em 1894 (MENA; HOBBS, 2010; BEWLEY-TAYLOR; BLICKMAN; JELSMA, 2014; VALOIS, 2019). No entanto, aproveitando-se de sua soberania bélica e capital, os EUA expandiram a sua política interna proibicionista para as demais nações e, em 1961, na Convenção Única dos Entorpecentes, a maconha tornou-se uma substância proscrita e adicionada à lista $\mathrm{I}$, que incluiu as substâncias consideradas com alto poder de adição e potencial de abuso, bem como à lista IV, que a considerou danosa e sem potencial terapêutico (BEWLEY-TAYLOR; BLICKMAN; JELSMA, 2014).

Entretanto, os estudos científicos sobre a Cannabis continuaram avançando e nos anos 1960 a equipe de pesquisa do Professor Raphael Mechoulam isolou e sintetizou o canabidiol (CBD) e o delta-9-tetrahidrocanabinol (THC). No final dos anos 1980, o sistema endocanabinoide começou a ser elucidado (PERTWEE, 2009).

Além dos avanços científicos sobre a estrutura da planta, diversos estudos multidisciplinares realizados ao longo do tempo mostravam que a propaganda que se fazia sobre os malefícios da maconha, relacionando-a à violência, criminalidade e grandes danos à saúde, não correspondiam à realidade, embora algumas pessoas pudessem de fato desenvolver quadros psicóticos por já terem uma propensão a eles (NATIONAL COMMISSION.., 1972). Um exemplo destes estudos foi o que originou o Relatório Schafer, solicitado pelo Governo Nixon. Diante desses relatórios, alguns estados estadunidenses descriminalizaram a substância, a exemplo de Oregon, em 1973, e da Califórnia, em 1975. No entanto, o Governo Nixon manteve a guerra às drogas que havia sido decretada em 1971.

$\mathrm{Na}$ década de 1990, o uso medicinal da maconha começou a ser regulamentado, inicialmente na Califórnia em 1996, a partir da Proposição 215, seguido por Israel em 1999 e Canadá em 2001. Apesar disto, o Órgão Internacional de Controle de Entorpecentes da ONU continuou pressionando por políticas proibicionistas e punitivistas (BEWLEY-TAYLOR; BLICKMAN; JELSMA, 2014). 
Em 2009, a Comissão Latino-Americana sobre Drogas e Democracia publicou uma declaração na qual expôs a falência da "guerra às drogas" e suas consequências para a região, destacando os "altíssimos custos humanos e sociais" que tal política representava. A Comissão Global de Políticas sobre Drogas (CGPD) corroborou esse posicionamento em 2011. As duas comissões se posicionaram a favor de uma revisão quanto à classificação da Cannabis nos acordos internacionais. O Uruguai foi o primeiro país a fazer uma regulamentação mais amplificada, que incluiu o uso medicinal e social da planta em 2014, sendo seguido pelo Canadá em 2018 e, em março de 2021, foi a vez do México.

A pressão de um movimento social, constituído principalmente por mães inspiradas no caso de uma criança californiana que conseguiu reduzir a frequência de crises convulsivas com o uso da Cannabis, fez com que a Agência Nacional de Vigilância Sanitária (Anvisa) iniciasse uma regulamentação para o uso medicinal da maconha no Brasil. Outras condições de saúde além da epilepsia foram sendo incorporadas no tratamento com as substâncias da planta, pois diversos estudos foram mostrando as possibilidades e a segurança do seu uso, que, indicado a partir do conhecimento prévio de possíveis efeitos adversos, permite que estes possam ser controlados.

Com o avanço das pesquisas e do uso medicinal da maconha, em 2019, a Organização Mundial de Saúde fez sete recomendações para a reclassificação da Cannabis nas convenções internacionais, mas apenas uma delas foi aceita em votação, realizada em dezembro de 2020. A planta foi retirada da lista IV da Convenção de 1961, o que significou o reconhecimento do potencial terapêutico da substância. É importante ressaltar que o Brasil se posicionou, oficialmente, contra todas as recomendações.

\section{Os discursos contemporâneos da psiquiatria no Brasil}

Embora a regulamentação do uso medicinal da maconha no Brasil já tenha sido iniciada pela Anvisa, ainda há disputas dentro do campo psiquiátrico nacional para validação terapêutica. O debate que é feito no país não tem conseguido desvincular o uso medicinal do uso problemático da substância, e por vezes fica concentrado em possíveis efeitos adversos que não são possíveis de serem generalizados. Isto acaba impedindo um avanço da regulação para o uso medicinal e para pesquisas com a planta, que se tornam extremamente necessários, visto o aumento de pessoas que buscam por essa tecnologia de saúde para o alívio dos seus sofrimentos e precisam ter melhor acesso a produtos seguros, além da necessidade de mais pesquisas científicas que refinem as condutas clínicas dos prescritores.

As entidades analisadas na pesquisa - o CFM e a ABP, que contam com a composição exclusiva de médicos - vêm se posicionando de forma 


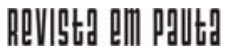

\} A TRAGÉDIA DO PRECONCEITO - FABRÍCIO, P. C.; AMARANTE, P.\}

DOI: $10.12957 /$ REP.2022.63528

divergente das entidades que compõem a PBPD (Cebes, Abrasco, Abramd e Abrasme), tanto em relação à política sobre drogas e sobre a assistência aos usuários de substâncias, quanto ao uso medicinal da maconha.

Desde 2015, quando o Supremo Tribunal Federal (STF) começou a julgar a constitucionalidade do artigo 28 da Lei ${ }^{\circ}$ 11.343/2006, a ABP e o CFM iniciaram uma série de notas e manifestações públicas que incluíram a política sobre drogas e maconha. $\mathrm{O}$ artigo 28 ao qual se referiu o julgamento de constitucionalidade traz o seguinte texto:

Art. 28. Quem adquirir, guardar, tiver em depósito, transportar ou trouxer consigo, para consumo pessoal, drogas sem autorização ou em desacordo com determinação legal ou regulamentar será submetido às seguintes penas:

I - advertência sobre os efeitos das drogas;

II - prestação de serviços à comunidade;

III - medida educativa de comparecimento a programa ou curso educativo.

$\S 1^{\text {o }}$ Às mesmas medidas submete-se quem, para seu consumo pessoal, semeia, cultiva ou colhe plantas destinadas à preparação de pequena quantidade de substância ou produto capaz de causar dependência física ou psíquica.

$\S 2$ o Para determinar se a droga destinava-se a consumo pessoal, $o$ juiz atenderá à natureza e à quantidade da substância apreendida, ao local e às condições em que se desenvolveu a ação, às circunstâncias sociais e pessoais, bem como à conduta e aos antecedentes do agente.

$\S 3$ o As penas previstas nos incisos II e III do caput deste artigo serão aplicadas pelo prazo máximo de 5 (cinco) meses.

$\S 4^{\circ} \mathrm{Em}$ caso de reincidência, as penas previstas nos incisos II e III do caput deste artigo serão aplicadas pelo prazo máximo de 10 (dez) meses.

§ $5^{\circ}$ A prestação de serviços à comunidade será cumprida em programas comunitários, entidades educacionais ou assistenciais, hospitais, estabelecimentos congêneres, públicos ou privados sem fins lucrativos, que se ocupem, preferencialmente, da prevenção do consumo ou da recuperação de usuários e dependentes de drogas.

$\S 6^{\circ}$ Para garantia do cumprimento das medidas educativas a que se refere o caput, nos incisos I, II e III, a que injustificadamente se recuse o agente, poderá o juiz submetê-lo, sucessivamente a:

I - admoestação verbal;

II - multa.

$\S 7^{\circ} \mathrm{O}$ juiz determinará ao Poder Público que coloque à disposição do infrator, gratuitamente, estabelecimento de saúde, preferencialmente ambulatorial, para tratamento especializado. (BRASIL, 2006, n. p. - Grifo nosso).

No julgamento, o relator, ministro Gilmar Mendes, e os ministros Edson Fachin e Luís Roberto Barroso, posicionaram-se a favor da inconstitucionalidade do artigo. As entidades médicas (CFM e ABP), em uma nota 
conjunta oficial dirigida ao Supremo Tribunal Federal, se posicionaram de forma favorável ao artigo, com as seguintes justificativas:

1. Vivemos uma grave epidemia do consumo de drogas que é, hoje, o maior problema de Saúde Pública e Segurança do país. O uso de drogas lícitas e ilícitas está atrás da maioria dos latrocínios, dos homicídios por causas banais, dos acidentes com veículos e dos suicídios. Além de ser a maior causa da violência doméstica e do aumento de casos da AIDS e de outras enfermidades agudas e crônicas entre os usuários.

2. A não criminalização do uso levaria à percepção social de que está liberado o consumo drogas, hoje ilícitas, o que facilitaria sua circulação e o aumento desse consumo principalmente entre os jovens. Na prática iria ser possível andar com drogas em qualquer ambiente, sem risco de qualquer punição. Isso reforçaria muito a multiplicação dos usuários. Paradoxalmente seria permitido o consumo, mas proibida a venda. O aumento do consumo levaria ao aumento da oferta, que seria feita justamente pelos traficantes. Além de aumentar o número de usuários e dos dependentes químicos das drogas, iria se fortalecer, e muito, o tráfico clandestino.

3. Os defensores da liberação das drogas no Brasil confundem a não existência de uma política integrada de enfrentamento ao problema, com a impossibilidade de fazer algo. Assim deduzem que é melhor liberar. Culpam a lei pelo aumento de presos no país, mas escondem que esse aumento é causado diretamente pela epidemia que aumenta a circulação das drogas, aumentando o número de traficantes numa escala gigantesca. A verdade é que o aumento do número de presos por tráfico acontece muito mais em função do momento da epidemia de Crack, que multiplica rapidamente usuários e traficantes, do que pela Lei, que considera crime, mas não prende pelo uso. Todos os países que passaram por epidemias de consumo de drogas, e que agiram com rigor, diminuindo a oferta de drogas nas ruas reduziram a epidemia e hoje tem grande diminuição no número de apenados e de presídios. (ABP; CFM, 2015, n. p.).

Sobre as questões apresentadas pela ABP e pelo CFM, há contrapontos que precisam ser avaliados com atenção, pois as entidades têm produzido discursos que não encontram respaldo em estudos do campo das ciências sociais, assim como no campo jurídico e de segurança pública. Para além disso, vêm corroborando com políticas públicas desastrosas que geram um grande sofrimento para parcela da sociedade, colocando essas pessoas em situação de vulnerabilidade.

A antropóloga Borges (2019) afirmou que a "guerra às drogas" tem centralidade na manutenção das desigualdades baseadas nas hierarquias raciais. Além disso, o discurso de epidemia de drogas e o amedrontamento da população a respeito das substâncias ilícitas cria as condições para a militarização de territórios periféricos, sob a alegação de enfrentamento a 


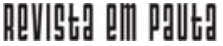

\} A TRAGÉDIA DO PRECONCEITO - FABRÍCIO, P. C.; AMARANTE, P.\}

DOI: $10.12957 /$ REP.2022.63528

um "problema social". Ela relatou que tal fato vem promovendo um sistema que se apoia na criminalização, no controle, na vigilância ostensiva desses territórios e no extermínio, que se justifica e tem sustentação social na suposição da participação de jovens da periferia no varejo de drogas. Para a autora, a "guerra às drogas" é central no encarceramento e genocídio da população negra brasileira. Ela demonstra relações históricas ligadas à fundação do país com suas políticas escravocratas, passando por todo processo de "não lugar" atribuído aos negros no período pós-Abolição no Brasil, incluindo as ideias eugenistas propagadas pela medicina no início do século XX, que se realocaram na política proibicionista (BORGES, 2019).

Um documento produzido pela Plataforma Brasileira de Políticas sobre Drogas (PBPD, 2016) concluiu que não há evidências que sustentem a relação entre criminalização ou não da posse de drogas com o seu consumo. Observou que o consumo de substâncias está relacionado a diversos fatores, sociais, culturais, psicológicos e biológicos. Além disso, considerou que, em vários países, após a constatação quanto ao fracasso da política de criminalização fomentada pelas convenções internacionais, passou-se a flexibilizar e a regulamentar, de diversas formas, a legislação sobre drogas. O documento apresenta um levantamento realizado em 2012 (ROSMARIN; EASTWOOD, 2012) no qual foi constatado que cerca de 20 países que flexibilizaram a legislação, seja despenalizando, seja descriminalizando o uso de substâncias, não apresentaram grandes alterações na prevalência de consumo, nem para baixo e nem para cima. Outra observação revelante se refere ao fato de que em países europeus vizinhos, com estruturas socioeconômicas semelhantes, a criminalização tem influenciado muito pouco na decisão de consumir substâncias ilícitas.

Nesse mesmo estudo, a PBPD afirmou que a descriminalização do uso de drogas não está associada ao aumento de crimes e que uma revisão sistemática (WERB et al., 2011) mostrou que países que adotaram leis mais severas contra usuários de substâncias, incluindo o encarceramento, apresentaram maiores taxas de episódios violentos, inclusive homicídios, o que estaria relacionado à dinâmica violenta do mercado ilícito de drogas. No entanto, observou-se que esse movimento se dá de forma diferente nos diversos países e que não há uma relação direta com o consumo de drogas em si, mas sim com as formas de funcionamento específicas do tráfico em países caracterizados por alto índice de violência.

Sobre a defesa da criminalização, que coloca em destaque o sistema penal, em vez de uma condução da saúde pública na questão das drogas, podemos usar para reflexão o apontamento do juiz Valois (2019, p. 22), que afirma que: "Há que se encerrar com essa outra irracionalidade, a de médicos receitarem prisão".

Ainda na argumentação da ABP e do CFM, ao considerar que o encarceramento vem crescendo por conta do "aumento do número de traficantes em uma escala gigantesca", foi possível notar que o tema foi 
tratado de forma pouco profunda. A PBPD, com base no documento do Departamento Penitenciário Nacional (MINISTÉRIO DA JUSTIÇA, 2014), observou que há grande seletividade nas pessoas que são encarceradas por tráfico de drogas, sendo em grande maioria pessoas com baixa escolaridade, baixa renda e pouca inserção no mercado de trabalho. Além disso, grande parte das pessoas submetidas à pena de prisão tinham sido flagradas em operação de rotina, desarmadas, sozinhas e portando quantidades pequenas das substâncias ilícitas (BOITEUX et al., 2009). A partir desses dados, avaliou que provavelmente há diversas pessoas que apenas consumiam substâncias ilícitas encarceradas como traficantes, e que, dentre elas, algumas fazem uso problemático, devendo estar recebendo cuidados em saúde (PBPD, 2016).

Ferrugem (2019) considerou que a Lei no 11343/2006, ao pretender distinguir usuário de traficante sem objetivar os critérios que possibilitem essa distinção, relegou aos agentes de segurança e aos juízes a avaliação subjetiva dessa questão. A aplicação do status de usuário ou traficante depende do lugar que o indivíduo ocupa na engrenagem do sistema social. Concluiu, assim, que o racismo institucional que fundamenta o aparelho repressor do Estado tem gerado um contingente populacional prisional de cerca de $62 \%$ de homens negros e $61 \%$ de mulheres negras, além de ter gerado um aumento expressivo de pessoas encarceradas por tráfico de drogas. Por fim, Ferrugem (2019) argumentou que há a necessidade de incluir a questão racial nos debates sobre políticas públicas, propondo alternativas à atual política sobre drogas. A autora ainda ressaltou que "são diversas as violações de direitos humanos, os traumas e perdas que essas pessoas e as suas famílias vêm sofrendo com a morte de um familiar por homicídio, com o processo penal e com o encarceramento" (FERRUGEM, 2019, p.111).

É necessário que esse sofrimento seja incluído na pauta das discussões de todas as instituições psiquiátricas e médicas no Brasil. Além disso, a medicina e a psiquiatria necessitam fazer uma reparação histórica devido à forma pela qual vêm contribuindo para o racismo estrutural, observando como, ainda, em seus discursos vêm auxiliando a continuidade da violência e do genocídio de jovens negros.

A restrição de liberdade não está circunscrita ao sistema penitenciário. Entidades como a ABP e o CFM têm defendido que a assistência em saúde para usuários de substâncias deve se basear em internações psiquiátricas ou em outras instituições fechadas. Um dos avanços da Lei ${ }^{\circ}$ 11.343/2006 foi o reconhecimento do tratamento baseado na redução de danos (TEIXEIRA et al., 2017). No entanto, com a alternância política que se estabeleceu nos últimos anos e com o surgimento de um movimento de contrarreforma psiquiátrica, grupos mais conservadores conseguiram implementar políticas de saúde mental, álcool e outras drogas contrárias à política de redução de danos, que vinha sendo implementada e que priorizava a 


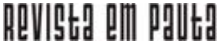

\} A TRAGÉDIA DO PRECONCEITO - FABRÍCIO, P. C.; AMARANTE, P. \}

DOI: $10.12957 /$ REP.2022.63528

liberdade e a autonomia dos usuários. Esses grupos começaram a estabelecer uma política na qual a abstinência tornou-se o foco a ser alcançado no tratamento - "que o paciente permaneça livre de drogas" (ABP, 2019, n.p.) e trouxeram para a centralidade da assistência o hospital psiquiátrico e as "comunidades terapêuticas".

Em junho de 2019, foi aprovada a Lei $\mathrm{n}^{\circ} 13.840$, que alterou a Lei $n^{\circ} 11.343 / 2006$. A lei, advinda do PL no 37/2013, de autoria do deputado Osmar Terra, reforçou a mudança na atenção às pessoas usuárias de álcool e outras substâncias. Priorizou o atendimento ambulatorial, em detrimento da assistência que vinha sendo executada e que focava em um atendimento multidisciplinar em Centros de Atenção Psicossocial especializados em álcool e outras drogas (Caps-AD).

A PBPD chamou atenção para o aumento do investimento nas "comunidades terapêuticas" e para a centralidade que essas instituições passaram a ocupar na Rede de Atenção Psicossocial (Raps), promovendo uma descaracterização da aposta do cuidado pautado na autonomia do usuário, que vinha se desenvolvendo em serviços comunitários e extrahospitalares. Consideraram que as "comunidades terapêuticas" representam um sistema fechado de cuidado, já que impõem restrições, inclusive de circulação aos indivíduos, o que remete a um sistema asilar. Mas não só isso, enfatizaram que, em inspeções realizadas pelo Conselho Federal de Psicologia (CFP) nas "comunidades terapêuticas", foram constatadas violações aos direitos humanos, inclusive com práticas violentas que colocam em risco os usuários acolhidos. O risco estaria também na falta de preparo para a condução de casos de maior gravidade relacionados ao abuso e à abstinência de substâncias. Outro ponto discutido foi a falta de comprovação científica de que a abstinência seria alcançada de forma mais efetiva nesse modo de acolhimento (PBPD, 2018).

Sobre o uso medicinal da maconha, em outubro de 2019, a ABP e o CFM publicaram o documento Decálogo sobre a maconha. Tratou-se de um posicionamento das entidades sobre o uso medicinal da planta. Nesse documento as instituições afirmaram que a Cannabis sp não poderia ser considerada um medicamento e, por isso, não existiria maconha medicinal; mesmo que existisse potencial terapêutico, os malefícios do uso da planta deveriam ser considerados.

Quase todos os posicionamentos da ABP e do CFM têm sido no sentido de questionar o uso terapêutico da Cannabis e, ao mesmo tempo, de se manifestar apoiando a permanência da política proibicionista e da criminalização da substância. Em suas manifestações públicas, essas instituições vêm restringindo o potencial terapêutico a uma única substância da Cannabis - o canabidiol (CBD) -, e somente para o uso em epilepsias de difícil controle. Afirmam não haver estudos que comprovem que o uso da planta seja seguro e enfatizam os problemas relacionados à sua utilização. Porém, os estudos sobre a utilização medicinal de Cannabis vêm crescendo 
exponencialmente nos últimos anos. Ao pesquisar no site do Pubmed pelo termo "medical Cannabis", é possível observar o gráfico que marca um estudo em 1870, crescendo para 1.513 estudos realizados no ano de 2020, totalizando 9.754 estudos ao longo desse período. Esses estudos abordaram o uso da planta para diferentes condições de saúde.

O número de países que têm alguma regulamentação para o consumo medicinal da Cannabis também vem aumentando no mundo e a tendência é de crescimento. O Conselho Federal de Medicina resolveu, em 2014, pela aprovação do uso compassivo do canabidiol para o tratamento de epilepsia de crianças e adolescentes com quadros refratários aos tratamentos convencionais (Resolução CFM 2113/2014), prevendo uma reavaliação em dois anos para inclusão de novos elementos científicos. No entanto, até o presente momento, ainda não houve essa atualização.

Tanto o CFM quanto a ABP têm lidado de forma bastante ambivalente quando se trata do uso medicinal da planta. Ao mesmo tempo em que negam o potencial terapêutico da Cannabis, como foi visto na publicação Decálogo sobre a maconha, de outubro de 2019, o CFM lançou em março de 2019, durante o Fórum da Maconha, o livro A tragédia da maconha. Embora tenha esse nome, na página 111, o CFM reconheceu evidências científicas conclusivas da eficácia terapêutica da Cannabis para dor crônica, como antiemético em pacientes submetidos à quimioterapia, e na espasticidade reportada por pacientes com esclerose múltipla. Ainda, constatou que há evidências moderadas nos distúrbios do sono, na fibromialgia, na dor crônica e na esclerose múltipla, assim como evidências limitadas para a Síndrome de Tourette, transtorno pós-traumático (Tept), transtorno de ansiedade social, espasticidade reportada pelo médico na esclerose múltipla e na inapetência e perda ponderal na Síndrome da Imunodeficiência Adquirida (Sida/Aids). A ABP também tem publicado artigos científicos que demonstram os efeitos medicinais da substância em sua revista científica, a Revista Brasileira de Psiquiatria (Brazilian Journal Psychiatry), principalmente em casos de ansiedade (LINARES et al., 2019; SCHIER et al., 2012).

O acirramento das políticas embasadas na lógica proibicionista no país, fato que tem relação direta com o aumento de poder de grupos conservadores e religiosos que negam a ciência, vem dificultando regulamentações mais abrangentes sobre a substância, mesmo diante do avanço das mudanças paradigmáticas em relação a Cannabis no século XXI. Ainda se tem uma regulação deficiente em relação ao uso medicinal da planta e a tentativa de potencializar políticas punitivistas que geram grande dano social para o país. É esperado um avanço legislativo no caminho para novas políticas mais contemporâneas sobre a Cannabis e uma reavaliação crítica e científica das instituições médicas psiquiátricas, na qual elas reconheçam e reavaliem o seu papel nos danos sociais e em relação à honestidade científica. 


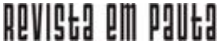

\} A TRAGÉDIA DO PRECONCEITO - FABRÍCIO, P. C.; AMARANTE, P. \}

DOI: $10.12957 /$ REP.2022.63528

\section{Considerações finais}

A psiquiatria tem lidado de formas distintas com as questões relacionadas à planta. Enquanto há um reconhecimento do seu potencial de tratamento pelas instituições multidisciplinares do campo psiquiátrico que constituem a PBPD, há uma resistência em admitir que a planta pode contribuir em diversas condições de saúde pelas instituições estritamente médicas, como a ABP e o CFM. Isso tem sido tratado de maneira bem desconcertante, pois, ao mesmo tempo em que as manifestações públicas negam as diversas propriedades terapêuticas da Cannabis, as publicações científicas das próprias instituições já não fazem o mesmo, o que permite supor que essas instituições não estão se posicionando publicamente orientadas pelas evidências que já possuem.

Tal fato é um grande problema, uma vez que acaba prejudicando pessoas que precisam fazer o uso medicinal da maconha e enfrentam várias dificuldades, seja por preconceitos, seja pela propagação de mitos construídos ao longo da história, pelo conservadorismo com o qual essas entidades médicas se associaram nos últimos tempos, ou, ainda, pelos riscos ocasionados pela falta de regulamentação que garanta a segurança e o acesso.

Como se não bastassem os obstáculos para o acesso a essa tecnologia de saúde, as entidades médicas do campo psiquiátrico vêm defendendo uma política proibicionista e punitivista, que tem ocasionado danos sociais irreparáveis e que afetam a liberdade individual, tanto no âmbito da saúde, com propostas de tratamento em instituições fechadas, quanto no campo jurídico, com a defesa da criminalização de pessoas que optam pelo uso das drogas. Embora elas enfatizem que todos os indivíduos punidos com prisão pertençam ao tráfico, isso não tem se mostrado realidade nas pesquisas realizadas no campo social, como também em pesquisas jurídicas e de segurança pública.

As práticas discursivas da ABP e do CFM produzem consequências sociais que resultam na superposição de vulnerabilidades, como estigmatização, dificuldade de acesso ao tratamento, encarceramento e sofrimento de parcela da população. Esta fica à margem de estratégias de cuidado em saúde e submetida às violências de Estado pela continuidade de uma política de "guerra às drogas".

Diante das divergências, é importante ressaltar que a busca por tratamento com a Cannabis está em crescimento em diversos lugares do mundo, incluindo o Brasil. Com isso, são necessários mais estudos clínicos que possam refinar a utilização dessa ferramenta terapêutica na população, como sempre é ressaltado por todas as entidades, sejam exclusivamente médicas, sejam multidisciplinares. Para isso, é importante que haja regulamentações que permitam o acesso mais ampliado à planta, com os mais diversos quimiotipos, para pesquisas e estabilização de cepas com a fina- 


\section{ReVIIStg all paUt?}

\} A TRAGÉDIA DO PRECONCEITO - FABRÍCIO, P. C.; AMARANTE, P.\}

DOI: $10.12957 /$ REP.2022.63528

lidade do uso medicinal. Políticas públicas que garantam acesso aos produtos a todas as pessoas que deles necessitem para a melhora da qualidade de vida são fundamentais, além de uma guinada para políticas sobre drogas que direcionem o uso da substância para a saúde pública. 


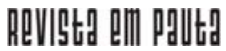

\} A TRAGÉDIA DO PRECONCEITO - FABRÍCIO, P. C.; AMARANTE, P. \}

DOI: $10.12957 /$ REP.2022.63528

\section{Referências}

ABP; CFM. Nota oficial. Supremo Tribunal Federal, 10 set. 2015. Disponível em: http://abpbrasil.websiteseguro.com/portal/wp-content/upload/2016/11/ nota_oficial-setembro_15.pdf. Acesso em: 19 de jun. 2020.

ABP. Nota oficial. Considerações à nota técnica 11/2019 do Ministério da Saúde sobre a nova Política Nacional de Saúde Mental e Drogas, 13 fev. 2019. Disponível em: http://abpbrasil.websiteseguro.com/portal/wpcontent/upload/2019/05/02-05_Considerações_ABP_CFM_ABIPD_FENAM_ FENAEMD.pdf. Acesso em 19 de jun, 2020.

BEWLEY-TAYLOR, D.; BLICKMAN, T.; JELSMA, M. The rise and decline of cannabis prohibition. Jubels, Amsterdam, mar. 2014.

BOITEUX, L. et al. Sumário executivo relatório de pesquisa "Tráfico de drogas e Constituição". Secretaria de Assuntos Legislativos do Ministério da Justiça (SAL), jul. 2009. Disponível em: http://pensando.mj.gov.br/wpcontent/uploads/2015/07/01Pensando_Direito3.pdf. Acesso em: 02 ago. 2020.

BORGES, J. Encarceramento em massa. São Paulo: Pólen, 2019.

BRASIL. Lei no 11.343. 2006. Disponível em: <http://www.planalto.gov.br/ ccivil_03/_ato2004-2006/2006/lei/l11343.htm>. Acesso em: 8 mar. 2020.

DORIA, R. Os fumadores de maconha: efeitos e males do vício. In: MINISTÉRIO DA SAÚDE. Maconha. Coletânea de trabalhos brasileiros. Brasília: Serviço Nacional de Educação Sanitária, 1958.

FERRUGEM, D. Guerra às drogas e a manutenção da hierarquia racial. Belo Horizonte: Letramento, 2019.

FRANÇA, J. M. C. História da maconha no Brasil. São Paulo: Três Estrelas, 2018.

LINARES, I. et al. Cannabidiol presents an inverted U-shaped dose-response curve in a simulated public speaking test. Braz J Psychiatry, v. 41, n. 1, 2019.

MENA, F.; HOBBS, D. Narcophobia: drugs prohibition and the generation of human rights abuses. Trends in Organized Crime, v. 13, n. 1, mar. 2010. MINISTÉRIO DA JUSTIÇA. Levantamento nacional de informações penitenciárias (Infopen). Brasília, jun. 2014.

NATIONAL COMMISSION on marihuana and drug abuse. Marihuana: a signal of misunderstanding, mar. 1972. Disponível em: http://www.drug library.org/schaffer/library/studies/nc/ncmenu.htm. Acesso em: 17 jan. 2020. 
PBPD. Dossiê descriminalização das drogas e o STF, 6 dez. 2016. Disponível em: https://pbpd.org.br/publicacao/dossie-descriminalizacao-das-drogas-eo-stf/. Acesso em: 02 ago 2020.

PBPD. Nota técnica sobre comunidades terapêuticas, 21 jun. 2018. Disponível em: https://pbpd.org.br/publicacao/nota-tecnica-sobre-comuni dades-terapeuticas/. Acesso em: 02 ago. 2020.

PERTWEE, R. G. Cannabinoid pharmacology: the first 66 years: Cannabinoid pharmacology. British Journal of Pharmacology, v. 147, n. S1, 2 fev. 2009. ROSMARIN, A.; EASTWOOD, N. A quiet revolution: drug decriminalisation policies in practice across the globe. London: Release Drugs, 2012. Disponível em: https://www.opensocietyfoundations.org/uploads/8c6213b89a9f-453a-9702-ff832f29afa5/release-quiet-revolution-drugdecriminalisation-policies-20120709.pdf. Acesso em: 16 jan. 2021.

SANTOS, R. G. Um panorama sobre a maconha.2009. Disponível em: www.neip.info. Acesso em: 16 jan. 2021.

SCHIER, A. et al. Cannabidiol, a Cannabis sativa constituent, as an anxiolytic drug. Braz J Psychiatry, v. 34, n. supl. 1, 2012.

SPINK, M. J. et al. Práticas discursivas e produção de sentidos no cotidiano. Centro Edelstein de pesquisas sociais, 2013.

TEIXEIRA, M. B. et al. Tensões paradigmáticas nas políticas públicas sobre drogas: análise da legislação brasileira no período de 2000 a 2016. Ciência e Saúde Coletiva, v. 22, n. 5, maio 2017.

VALOIS, L. C. O direito penal da guerra às drogas. [s.I: s.n.], 2019.

WERB, D. et al. Effect of drug law enforcement on drug market violence: a systematic review. International Journal of Drug Policy, v. 22, n. 2, mar. 2011.

DOI: $10.12957 /$ rep.2022.63528

Recebido em 28 de setembro de 2021. Aprovado para publicação em 16 de outubro de 2021.

A Revista Em Pauta: Teoria Social e Realidade Contemporânea está licenciada com uma Licença Creative Commons Atribuição 4.0 Internacional. 